\title{
Rancang Bangun Sistem Monitoring Pada Bendungan Dengan Menggunakan Metode Fuzzy Tahani Berbasis Mikrokontroler
}

\author{
Hengki Sikumbang ${ }^{1}$; Indrianto $^{2}$; Garang Syahputra Siregar ${ }^{3}$ \\ 1,2, 3 Jurusan Teknik Informatika, Institut Teknologi PLN \\ ${ }^{1}$ hengki@itpln.ac.id
}

\begin{abstract}
This research designed a monitoring system on dam by using fuzzy tahani method based on Microcontroller. This tool is designed to be used as monitoring on the Katulampa Dam. This tool consists of Raspberry module Pi 3 model B, ultrasonic sensors, resistors and android. The monitoring system on the dam is used to inform the user/citizen when the water in the dam has exceeded the specified height limit and notify the user of the appliance if there is a possibility of flooding, so that residents around the dam can be alert and avoid danger caused by flood. So that with the tool is expected to provide solutions to residents around the dam and residents whose homes are near the dam river flow in case of sudden danger or flood within 24 hours in real time and can minimize casualties due to flooding. By using application module on android that can give notification sms to appliance user and citizen, hence citizen around the dam will be more secure and protected from danger caused by flood and can minimize victim or other loss caused by flood.
\end{abstract}

Keywords : Raspberry Pi 3 B model, Ultrasonic Sensor, Monitoring System

\begin{abstract}
ABSTRAK
Pada penelitian ini dirancang sebuah sistem monitoring pada bendungan dengan menggunakan metode fuzzy tahani berbasis mikrokontroler. Alat ini dirancang untuk digunakan sebagai monitoring pada Bendung Katulampa. Alat ini terdiri dari modul Raspberry Pi 3 model B, sensor ultrasonik, resistor dan Android. Sistem monitoring pada bendungan digunakan untuk memberitahukan kepada si pengguna/warga apabila air pada bendungan telah melebihi batas ketinggian yang ditentukan dan memberitahukan kepada si pengguna alat/warga apabila kemungkinan akan terjadi banjir, sehingga warga disekitar bendungan bisa waspada dan dapat terhindar dari bahaya yang disebabkan banjir. Sehingga dengan adanya alat ini diharapkan dapat memberikan solusi kepada warga sekitar bendungan dan warga yang rumahnya berada di dekat aliran sungai bendungan apabila terjadi bahaya atau banjir secara tiba-tiba dalam waktu 24 jam secara real time dan dapat meminimalisir korban akibat banjir. Dengan menggunakan modul aplikasi pada android yang dapat memberikan notifikasi sms kepada pengguna alat dan warga, maka warga disekitar bendungan akan semakin aman dan terhindar dari bahaya yang disebabkan oleh banjir dan dapat meminimalisir korban atau kerugian lainnya yang disebabkan oleh banjir.
\end{abstract}

Kata kunci : Raspberry Pi 3 model B, Sensor Ultrasonik, Sistem Monitoring 


\section{PENDAHULUAN}

Indonesia merupakan negara yang memiliki curah hujan cukup tinggi. Pada musim penghujan hampir keseluruhan daerah diguyur hujan dengan intensitas yang tinggi. Musim hujan biasanya berlangsung sampai dengan 4 bulan. Hal ini sebenarnya merupakan keuntungan dikarenakan jarang terjadi kekeringan di wilayah Indonesia. Tentunya air sangat bermanfaat bagi kehidupan sebagai bahan konsumsi ataupun pengairan pada wilayah pertanian.[1] Di sisi yang lain masalah yang tiap tahun di hadapi oleh masyarakat di kota besar seperti di Jakarta adalah banjir. Kawasan perumahan di sekitaran sungai besar juga tidak luput dari rawan banjir. Minimnya ruang terbuka hijau membuat resapan air di daerah tersebut menjadi buruk. Membuang sampah pada aliran air juga menjadi faktor yang memperparah aliran air [2][1].

Objek dalam penelitian ini adalah Bendungan Katulampa. Selama ini pemantauan ketinggian air sungai/bendungan yang dilakukan masih menggunakan alat-alat manual berupa skala ketinggian air yang diletakkan di pinggiran sungai/bendungan. Hal ini memiliki keterbatasan terutama terhadap penumpukan sedimen di dasar sungai/bendungan, sehingga mengurangi akurasi dari segi pengukuran ketinggiannya. Untuk pengecekan ketinggian air sendiri juga masih manual yaitu dengan cara petugas terjun langsung kelapangan untuk memonitoring ketinggian air, dimana hal ini sangat menyulitkan apabila harus memantau ketinggian air selama 24 jam. Mengingat akan pentingnya pemantauan atau sistem monitoring terhadap ketinggian air sungai/bendungan terutama pada daerahdaerah dengan tinggi daratan yang lebih rendah dari permukaan laut, untuk itu perlu dibuat suatu alat yang dapat mengukur ketinggian sungai/bendungan secara real time dan memberitahukan kepada warga disekitar bendungan agar waspada apabila kemungkinan terjadi banjir atau bencana lainnya. Sistem monitoring pada bendungan adalah suatu sistem pemantauan yang digunakan untuk dapat meminimalisir bencana yang disebabkan oleh banjir, akibat air pada bendungan meluap, akibat sedimentasi maupun disebabkan oleh bencana lainnya seperti sampah.

Penelitian yang dilakukan oleh Eli Zahrotin dkk [3] hasil yang di dapat adalah sensor kapasitif untuk mengukur ketinggian air telah berhasil difabrikasi. Sensor level air berbasis prinsip kapasitif dengan menggunakan silinder koaksial yang terdiri atas dua buah silinder dengan jari-jari dalam dan luar berturut-turut sebesar 0,995 dan 1,435 cm, serta mempunyai tinggi $82 \mathrm{~cm}$. Penelitian dilakukan dengan menggunakan air dan udara sebagai pengisi ruang diantara kedua silinder, dimana sistem ini akan mempunyai sifat yang sama dengan kapasitor. Sehingga akan mempunyai nilai kapasitif tertentu tergantung dari level (ketinggian) air. Penelitian lain yang dilakukan oleh Saleh, Khairul., Fauziyah., Hadi., \& Freddy [4] hasil yang di dapat adalah Sensor yang digunakan adalah sensor ultrasonik yang dapat mengukur jarak maksimum hingga $300 \mathrm{~cm}$ dengan resolusi $1 \mathrm{~cm}$. Berat total alat yang dirancang lebih kurang 0,7 kilogram. Cara kerja alat ini yaitu mikrokontroller di aktifkan dengan tegangan $5 \mathrm{~V}$ dari sumber tegangan dan melakukan instruksi dari software yang telah di desain. Sensor ultrasonik memancarkan gelombang ultrasonik melalui transmitter sesuai dengan kontrol mikrokontroller dengan kecepatan di udara $344 \mathrm{~m} / \mathrm{s}$, mengenai objek dan memantul kembali menuju receiver. Sensor mengeluarkan pulsa output high pada pin SIG setelah memancarkan gelombang ultrasonik dan setelah gelombang terdeteksi sensor ultrasonik akan membuat output low pada pin SIG. Lebar pulsa high akan sesuai dengan lama waktu tempuh gelombang ultrasonik untuk 2 kali jarak ukur dengan objek. Lebar pulsa minimum adalah $115 \mu$ s dan pulsa maksimumnya 18,5 ms. Jarak yang didapatkan kemudian akan disimpan di dalam flashdisk dan ditampilkan pada monitor apabila masih terhubung. Alat ini mampu memantau selama 24 jam dan menyimpan data maksimum 65535 data.

Pada penelitian ini menggunakan metode fuzzy tahani berbasis mikrokontroler. Alat tersebut dapat memberitahukan si pengguna/warga jika air sudah melebihi batas ketinggian yang sudah 
ditentukan dengan memberikan notifikasi sms kepada pengguna alat dengan menggunakan aplikasi pada Android untuk peringatan terhadap warga disekitar bendungan.

\section{METODE/PERANCANGAN PENELITIAN}

\subsection{Perancangan Penelitian}

Penelitian yang akan dilakukan bersifat kuantitatif, artinya penelitian ini berdasarkan perhitungan yang menggunakan metode tertentu. Metode yang digunakan adalah Fuzzy Logic Controller. Dimana penggunaan kondisi dan inputan dari komponen-komponen alat akan diproses dan dihitung sehingga menghasilkan suatu outputan berupa aksi yang dilakukan komponen dan informasi untuk dikirim ke pengguna. Berikut blok diagram sistem yang dibuat oleh penulis dalam pembuatan alat ini:

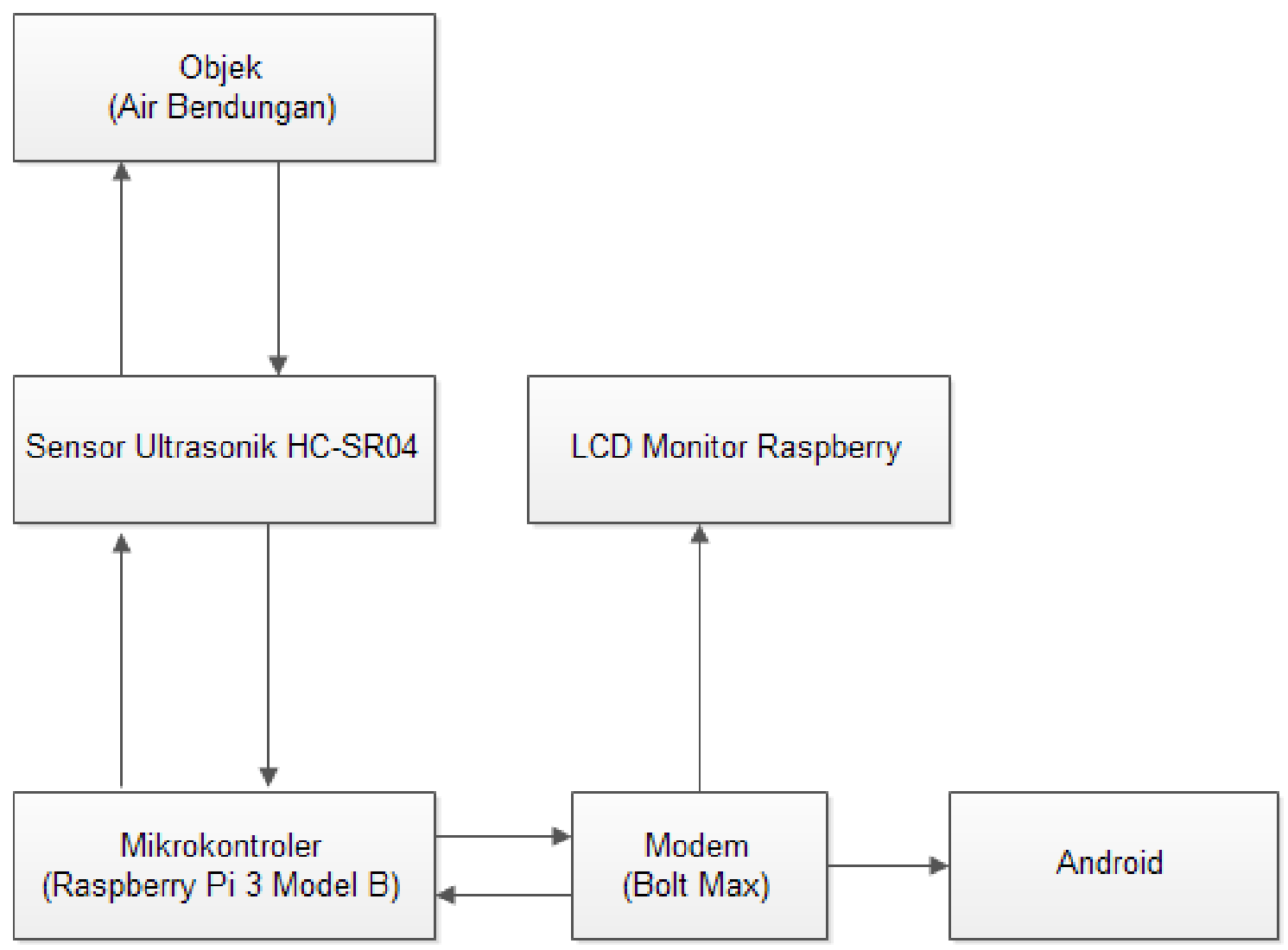

Gambar 1. Perancangan Blok Diagram Sistem

\subsection{Metode Logika Fuzzy Tahani}

Metode Fuzzy akan digunakan dalam mengukur data ketinggian air dari hasil yang didapat dari nilai sensor ultrasonik HC-SR04. Metode Fuzzy Tahani digunakan untuk menghitung ketinggian pada sensor ultrasonik HC-SR-04. Jika ketinggian air sudah mencapai batas ketinggian yang sudah ditentukan, maka notifikasi akan muncul pada aplikasi katulampa di Android dan akan mengirimkan SMS keseluruh nomor hp yang sudah terdaftar di database. Sebagian besar basis data standar diklasifikasikan berdasarkan bagaimana data tersebut dipandang oleh user. Fuzzy Tahani mendefinisikan konsep dari relasi fuzzy dalam sebuah database sistem dengan menggunakan derajat keanggotaan[5] 


\subsection{Tahapan Dalam Perhitungan Logika Fuzzy}

Untuk mendapatkan nilai dari ketinggian air maka diperlukan beberapa tahapan-tahapan yaitu sebagai berikut :

1. Mendapatkan nilai awal dari sensor ultrasonuik HC-SR04 ketika alat menyala

2. Mendapatkan nilai baru setelah nilai awal setelah melakukan Langkah sebelumnya

3. Menyimpan dan menghitung data ketinggian pada Raspberry dengan menggunakan metode fuzzy tahani

4. Setelah mendapatkan nilai dari metode fuzzy tahani, maka data ketinggian akan dibandingkan mana nilai yang paling besar

5. Setelah itu data ketinggian akan ditampilkan pada Raspberry dan pada aplikasi katulampa di Android

\section{HASIL DAN PEMBAHASAN}

\subsection{Tahapan Rumus dan Perhitungan Logika Fuzzy}

1. Menentukan variabel fuzzy

Variabel fuzzy yang akan dibahas penelitian ini adalah sistem fuzzy ketinggian air pada bendung katulampa.

2. Menentukan himpunan fuzzy

Himpunan fuzzy ditentukan untuk mengelompokkan data berdasarkan variabel linguistik yang dinyatakan dalam fungsi keanggotaan. Tingkat ketinggian air yang digunakan adalah $0-250 \mathrm{~cm}$ atau setelah diubah kedalam bentuk persentase menjadi $0-100 \%$. Berdasarkan data variabel fuzzy diatas, maka dapat ditentukan himpunan fuzzy untuk ketinggian air adalah sebagai berikut :

Tabel 1. Pengelompokan Ketinggian Air

\begin{tabular}{|c|c|}
\hline Himpunan Fuzzy & Domain Nilai \\
\hline Normal & $0-50 \mathrm{~cm}$ atau $0-20 \%$ \\
\hline Siaga IV & $50-80 \mathrm{~cm}$ atau $20-32 \%$ \\
\hline Siaga III & $80-150 \mathrm{~cm}$ atau $32-60 \%$ \\
\hline Siaga II & $150-200 \mathrm{~cm}$ atau $60-80 \%$ \\
\hline Siaga I & $200-250 \mathrm{~cm}$ atau $80-100 \%$ \\
\hline
\end{tabular}

3. Menentukan fungsi keanggotaan

Berikut adalah fungsi keanggotaan yang digunakan untuk mengukur ketinggian air :

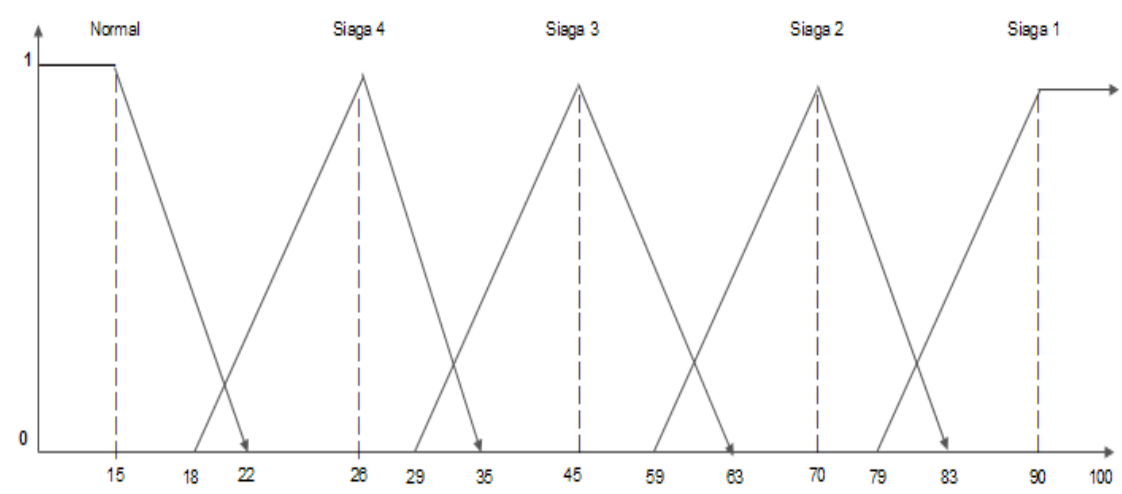

Gambar 2. : Himpunan Tingkat Ketinggian Air 
4. Menghitung derajat keanggotaan himpunan :

a. Fungsi keanggotaan Ketinggian Air

- Normal, Menggunakan Rumus Kurva Representasi Linier Turun

$$
\mu \text { Normal }[\mathrm{x}, \mathrm{a}, \mathrm{b}]=\left\{\begin{array}{cc}
1 & \\
(b-x) /(b-a) ; & a \leq x \leq b \\
0 & x \geq b
\end{array}\right.
$$

Contoh :

$$
\begin{aligned}
\text { Dimana }: x & \leq 15 \rightarrow \text { Normal }=1 \\
x & \geq 22 \rightarrow \text { Normal }=0 \\
15 & <x<22 \rightarrow \text { Normal }=22-\frac{x}{7}
\end{aligned}
$$

- Siaga IV, Menggunakan Rumus Kurva Representasi Linier Naik dan Turun

- Naik

$$
\begin{aligned}
& \mu \text { Siaga IV }[\mathrm{x}, \mathrm{a}, \mathrm{b}]=\left\{\begin{array}{cr}
0 & x \leq a \\
(x-a) /(b-a) ; & a \leq x \leq b \\
1 &
\end{array}\right. \\
& \text { - Turun } \\
& x \geq b
\end{aligned}
$$

$$
\mu \text { Siaga IV }[\mathrm{x}, \mathrm{a}, \mathrm{b}]=\left\{\begin{array}{cc}
1 & x \leq a \\
(b-x) /(b-a) ; & a \leq x \leq b \\
0 & x \geq b
\end{array}\right.
$$$$
\text { Contoh : }
$$

$$
\begin{aligned}
\text { Dimana }: x \leq 18 \text { V } x \geq 35 & \rightarrow \text { Siaga IV }=0 \\
18<x \leq 26 & \rightarrow \text { Siaga } I V=x-\frac{18}{8} \\
26 & <x<35 \rightarrow \text { Siaga } I V=35-\frac{x}{9}
\end{aligned}
$$

- Siaga III, Menggunakan Rumus Kurva Representasi Linier Naik dan Turun

- Naik

$$
\mu \text { Siaga III }[\mathrm{x}, \mathrm{a}, \mathrm{b}]=\left\{\begin{array}{cc}
0 & x \leq a \\
(x-a) /(b-a) ; & a \leq x \leq b \\
1 & x \geq b
\end{array}\right.
$$

- Turun

$$
\mu \text { Siaga III }[\mathrm{x}, \mathrm{a}, \mathrm{b}]=\left\{\begin{array}{cc}
1 & \\
(b-x) /(b-a) ; & a \leq x \leq b \\
0 & x \geq b
\end{array}\right.
$$

Contoh :

Dimana $: x \leq 29$ V $x \geq 63 \rightarrow$ Siaga $I I I=0$ 


$$
\begin{aligned}
29<x & \leq 45 \rightarrow \text { Siaga III }=x-\frac{29}{16} \\
& 45<x<63 \rightarrow \text { Siaga III }=63-\frac{x}{18}
\end{aligned}
$$

- Siaga II, Menggunakan Rumus Kurva Representasi Linier Naik dan Turun

- Naik

$$
\mu \text { Siaga II }[\mathrm{x}, \mathrm{a}, \mathrm{b}]=\left\{\begin{array}{cr}
0 & x \leq a \\
(x-a) /(b-a) ; & a \leq x \leq b \\
1 & x \geq b
\end{array}\right.
$$

- Turun

$$
x \leq a
$$

$$
\mu \text { Siaga II }[\mathrm{x}, \mathrm{a}, \mathrm{b}]=\left\{\begin{array}{cc}
1 & \\
(b-x) /(b-a) ; & a \leq x \leq b \\
0 & x \geq b
\end{array}\right.
$$

Contoh :

$$
\begin{aligned}
\text { Dimana }: x \leq 59 \text { V } x \geq 83 \rightarrow \text { Siaga } I I=0 \\
59<x \leq 70 \rightarrow \text { Siaga } I I=x-\frac{59}{11} \\
70<x<83 \rightarrow \text { Siaga } I I=83-\frac{x}{13}
\end{aligned}
$$

- Siaga 1, Menggunakan Rumus Kurva Representasi Linier Naik

$$
\mu \text { Siaga I }[\mathrm{x}, \mathrm{a}, \mathrm{b}]=\left\{\begin{array}{cr}
0 & x \leq a \\
(x-a) /(b-a) ; & a \leq x \leq b \\
1 & x \geq b
\end{array}\right.
$$

Contoh :

$$
\begin{aligned}
\text { Dimana }: x & \leq 79 \rightarrow \text { Siaga } I=0 \\
x & \geq 90 \rightarrow \text { Siaga } I=1 \\
79 & <x<90 \rightarrow \text { Siaga } I=x-\frac{79}{11}
\end{aligned}
$$




\subsection{Tampilan Aplikasi}
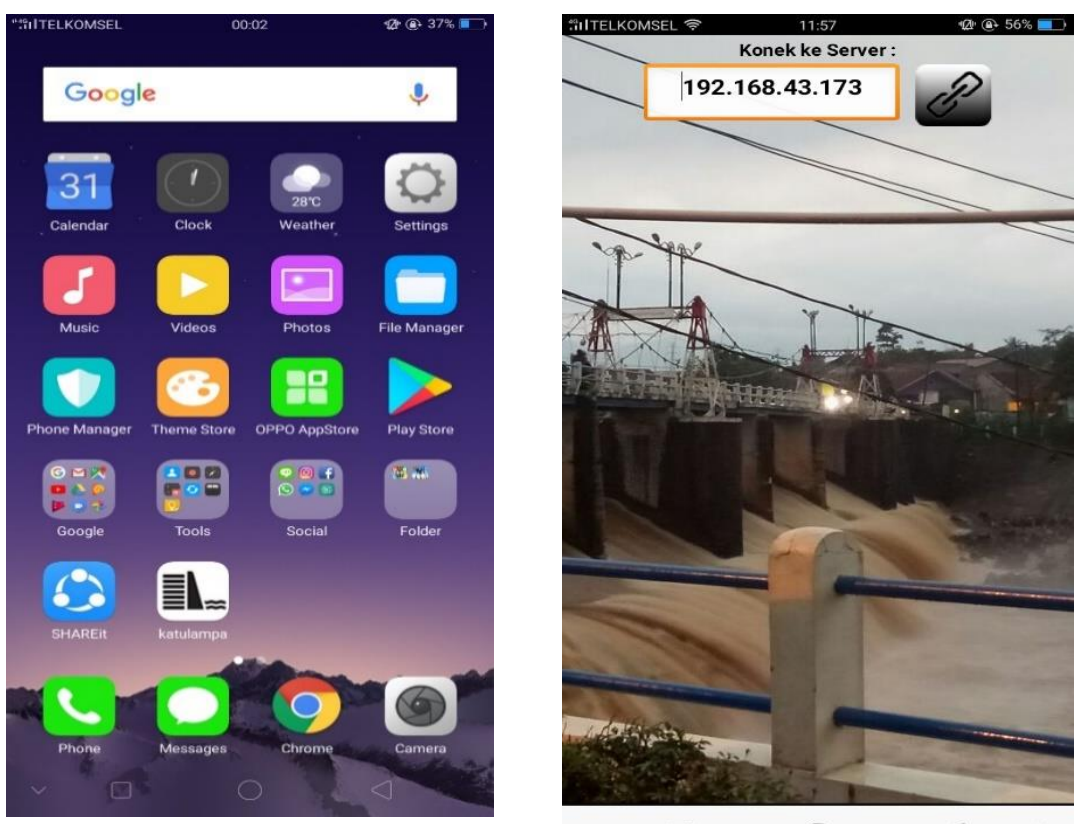

Gambar 3. Tampilan Aplikasi
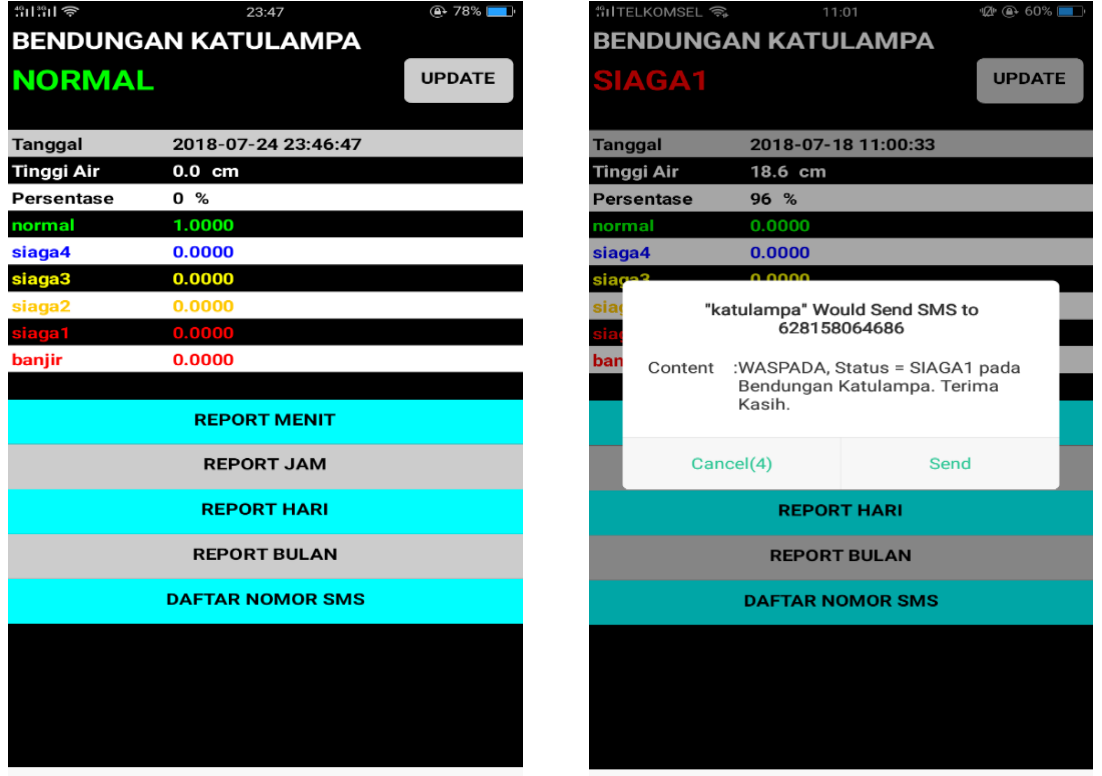

Gambar 4. Halaman Utama

Gambar 5. Notifikasi Pengiriman SMS

Hasil yang diperoleh dari penelitian ini adalah terbentuknya sebuah prototype "Rancang Bangun Sistem Monitoring Pada Bendungan Dengan Menggunakan Metode Fuzzy Tahani Berbasis Mikrokontroler". 
Tabel 2. Hasil Perbandingan Sistem

\begin{tabular}{|l|l|l|}
\hline No. & Sistem Lama & Sistem Baru \\
\hline 1. & $\begin{array}{l}\text { Monitoring ketinggian air dilakukan secara } \\
\text { manual }\end{array}$ & $\begin{array}{l}\text { Monitoring ketinggian air dilakukan melalui } \\
\text { aplikasi Android }\end{array}$ \\
\hline 2. & $\begin{array}{l}\text { Rekap data ketinggian air dilakukan dengan } \\
\text { cara manual. Caranya amati ketinggian air } \\
\text { terlebih dahulu dan ditulis dalam kertas }\end{array}$ & $\begin{array}{l}\text { Rekap data dapat dilakukan melalui aplikasi } \\
\text { Android. Dimana dalam aplikasi tersebut } \\
\text { terdapat report pdf data permenit, perjam, } \\
\text { perhari dan perbulan }\end{array}$ \\
\hline 3. & $\begin{array}{l}\text { Menampilkan grafik data harus direkap } \\
\text { terlebih dahulu di excel }\end{array}$ & $\begin{array}{l}\text { Grafik ditampilkan langsung di Android dan } \\
\text { layar monitor. }\end{array}$ \\
\hline 4. & $\begin{array}{l}\text { Belum terdapat alat untuk melakukan } \\
\text { monitoring }\end{array}$ & $\begin{array}{l}\text { Ketinggian dapat dimonitoring dengan } \\
\text { menggunakan Raspberry Pi 3 Model B }\end{array}$ \\
\hline 5. & $\begin{array}{l}\text { Belum memiliki alat untuk memonitoring } \\
\text { ketinggian air }\end{array}$ & $\begin{array}{l}\text { Menggunakan Raspberry dan sensor ultrasonik } \\
\text { HC-SR04 untuk memonitoring ketinggian air }\end{array}$ \\
\hline 6. & $\begin{array}{l}\text { Ketinggian air tidak dapat dimonitoring } \\
\text { selama 24 jam }\end{array}$ & $\begin{array}{l}\text { Ketinggian air dapat dimonitoring selama 24 } \\
\text { jam dengan menggunakan alat dan aplikasi yang } \\
\text { sudah dibuat. }\end{array}$ \\
\hline 7. & $\begin{array}{l}\text { Belum memiliki aplikasi untuk memonitoring } \\
\text { ketinggian air pada bendungan. }\end{array}$ & $\begin{array}{l}\text { Sudah memiliki aplikasi pada Android untuk } \\
\text { memonitoring ketinggian air pada bendungan. }\end{array}$ \\
\hline 8. & $\begin{array}{l}\text { Bahaya banjir dideteksi dengan cara melihat } \\
\text { ketinggian air langsung ke bendungan. }\end{array}$ & $\begin{array}{l}\text { Bahaya banjir dapat dilihat melalui aplikasi dan } \\
\text { mempunyai output notifikasi SMS apabila } \\
\text { terdeteksi bahaya banjir. }\end{array}$ \\
\hline
\end{tabular}

\subsection{Implikasi Penelitian}

Dalam kegiatan penelitian dan uji coba hasil yang telah dilakukan dengan memanfaatkan Raspberry sebagai otak dari alat untuk merancang sistem monitoring. Maka diperoleh suatu hasil dan uji coba dari sistem yang dibangun sebagai solusi untuk pemecahan masalah yang telah diuraikan sebagai berikut :

1. Dengan adanya sistem monitoring pada bendungan yang dibuat penulis, dapat menggantikan sistem monitoring dengan cara manual yang selama ini dipakai.

2. Model alat yang dibangun dapat menentukan ketinggian air pada bendung katulampa secara realtime selama 24 jam.

3. Sistem peringatan yang ada pada alat ini menggunakan aplikasi di Android dan notifikasi SMS untuk outputnya, sehingga ketinggian air dapat dimonitoring lewat aplikasi Android dan jika ketinggian air sudah melebihi batas ketinggian yang sudah ditentukan maka akan ada notifikasi SMS keseluruh nomor hp yang sudah terdaftar di database.

\section{KESIMPULAN DAN SARAN}

\subsection{Kesimpulan}

Dari hasil penelitian yang dilakukan mulai dari tahap awal hingga proses pengujian dibuat kesimpulan sebagaimana berikut :

1. Rancang bangun sistem monitoring ini ditujukan untuk petugas dan koordinator sup ciliwung bendung katulampa sebagai sistem monitoring ketinggian air pada bendungan.

2. Untuk membuat atau membangun sistem monitoring pada penelitian ini dilakukan menggunakan metode prototype dan metode logika fuzzy tahani. 
3. Pada perancangan penelitian ini terdiri dari perancangan perangkat keras yang meliputi komponen utama diantaranya Raspberry Pi 3 Model B, Sensor Ultrasonik HC-SR04 dan Android.

4. Sistem peringatan yang ada pada alat ini menggunakan aplikasi di Android dan notifikasi SMS untuk outputnya, sehingga ketinggian air dapat dimonitoring lewat aplikasi Android dan jika ketinggian air sudah melebihi batas ketinggian yang sudah ditentukan maka akan ada notifikasi SMS keseluruh nomor hp yang sudah terdaftar di database.

\subsection{Saran}

Adapun saran-saran yang dapat penulis berikan sebagai bahan pertimbagan untuk melakukan pengembangan penelitian selanjutnya adalah sebagai berikut :

1. Rancang bangun sistem monitoring ini belum dihosting dan belum bisa dimonitoring dari jarak yang jauh, sehingga untuk pengembangan selanjutnya hal ini dapat menjadi acuan untuk pengembang.

2. Dalam penulisan skripsi ini hanya menguji coba satu jenis sensor pengukur ketinggian yaitu Sensor Ultrasonik HC-SR04. Untuk pengembangan kedepannya penulis menyarankan agar mencoba sensor ketinggian yang lain agar dapat menjadi bahan perbandingan.

\section{UCAPAN TERIMAKASIH}

Penulis mengucapkan terimakasih kepada Kepala LPPM Institut Teknologi PLN Bapak Indrianto S.Kom., MT dan Kepala Sub Bagian Tata Usaha UPTD PSDA Wilayah Sungai CiliwungCisadane Bapak Drs. Yadi Darma Priyanjaya, M. Ap yang telah memberi dukungan dan membantu pelaksanaan penelitian ini.

\section{DAFTAR PUSTAKA}

[1] Tenggono, Alfred., Wijaya, Yovan, Kusuma, Erick., \& Welly (2015). Sistem Monitoring dan Peringatan Ketinggian Air Berbasis Web Dan Sms Gateway. STMIK PalComTech, Palembang. Vol. 5, No.2, Juli 2015, 119-129.

[2] Samijayani, O. N., Iftikar, F., Hariomurti, M., \& Astharini, D., (2013). Implementasi Sistem Sensor Sederhana untuk Peringatan Banjir melalui SMS. Jurnal Al-Azhar Indonesia Seri Sains dan Teknologi, Vol. 2, No.1, Maret 2013, 22-27

[3] Zahrotin, Eli., \& Endarko (2014). Rancang Bangun Sensor Kapasitif Untuk Level Air. Surabaya : Jurnal Berkala Fisika Vol.17, No.4, Oktober 2014, ISSN : 1410-9662, hal 129-138.

[4] Saleh, Khairul., Fauziyah., Hadi., \& Freddy (2013). Sistem Pemantauan Ketinggian Permukaan Air Berbasis Mikrokontroler Basic Stamp-2 Menggunakan Memory Stick Sebagai Penyimpan Data. PrOSIDing Semirata FMIPA Universitas Lampung, 2013, 511-515.

[5] Efendi, R., \& HIDayati, R. (2014). Aplikasi Fuzzy Database Model Tahani Dalam Memberikan Rekomendasi Pembelian Rumah Berbasis Web. Jurnal Pseudocode, Volume 1 Nomor 1, Februari 2014, ISSN 2355 - 5920, 32-43. 